\title{
Implante de um floculado de resina de mamona em alvéolo dental de rato
}

\section{Implantation of flakes of castor oil resin in rat dental alveolus}

\author{
Romeu Felipe Elias CALIXTO* \\ Juliana Mazzonetto TEÓFILO** \\ Luiz Guilherme BRENTEGANI*** \\ Teresa Lúcia LAMANO CARVALHO***
}

\begin{abstract}
CALIXTO, R. F. E.; TEÓFILO, J. M.; BRENTEGANI, L. G.; LAMANO CARVALHO, T. L. Implante de um floculado de resina de mamona em alvéolo dental de rato. Pesqui Odontol Bras, v. 15, n. 3, p. 257-262, jul./set. 2001.

Os objetivos do presente trabalho foram: 1) testar a biocompatibilidade de uma resina natural, derivada do óleo de mamona, implantada na cavidade de extração dental de ratos, e 2) estudar a possível interferência do material na cronologia do reparo alveolar. O material (AUG-EX, Poliquil Araraquara Polímeros Químicos Ltda., Araraquara - SP) foi implantado no alvéolo imediatamente após a extração do incisivo superior direito e os ratos foram sacrificados de 1 a 6 semanas após a extração ou extração + implante. As hemimaxilas foram descalcificadas e processadas para inclusão em parafina e obtenção de cortes semi-seriados, corados com hematoxilina-eosina. Os flocos da resina, de forma irregular e tamanho variável, localizaram-se entre os terços alveolares médio e cervical, inicialmente circundados por tecido de granulação e a seguir por quantidade progressivamente maior de tecido ósseo, no geral com a presença de um tecido conjuntivo interposto, mas em algumas áreas estabelecendo aparente osseointegração direta. Não houve persistência da reação inflamatória, mas observou-se pequena quantidade de células gigantes aderidas à superfície do material, em todos os períodos. A análise histométrica (contagem diferencial de pontos) do terço apical mostrou um atraso de $13 \%$ a $20 \%$ no reparo alveolar dos ratos implantados, com menor neoformação óssea associada a maiores volumes percentuais de tecido conjuntivo e de remanescentes do coágulo sangüíneo.
\end{abstract}

UNITERMOS: Biocompatibilidade; Ricinus communis; Resinas.

\section{INTRODUÇÃO}

Os problemas de difícil solução, na Medicina e Odontologia, incluem as falhas ósseas de grandes dimensões que, deixadas ao seu livre curso, não lograriam regenerar-se ou o fariam muito lentamente e de forma incompleta. Situações dessa natureza beneficiam-se do uso de biomateriais para reconstrução, substituição ou preenchimento dos defeitos, e as soluções mais previsiveis ainda são obtidas com a utilização dos enxertos ósseos que têm, no entanto, os inconvenientes da morbidade cirúrgica da fonte doadora e da disponibilidade limitada de material (enxertos ósseos autógenos) ou apresentam riscos de transmissão de infecção e de ativação imunológica do hospedeiro, além da desvantagem dos altos custos dos bancos de ossos (enxertos homógenos e heterógenos). Em vista disso, têm-se intensificado as pesquisas para o desenvolvimento de materiais aloplásticos que apre- sentem características adequadas de biocompatibilidade e osseointegração.

Relatos recentes mostram resultados promissores de uma resina poliuretana de origem vegetal, derivada do óleo de mamona, com possibilidade de aplicação em ortopedia e cirurgia plástica. Implantes da resina de mamona, de diferentes tamanhos e formas, têm-se mostrado biocompativeis em condições experimentais diversas: no interior de ossos longos e intra-articulares em coelhos ${ }^{5,14}$ e $\operatorname{ratos}^{12}$, na câmara anterior do olho de camundongos ${ }^{16} \mathrm{e}$ nos tecidos subcutâneos de ratos ${ }^{3}$. Visando acrescentar informações sobre sua biocompatibilidade e possibilidade de uso em áreas específicas da Medicina e Odontologia, o presente trabalho teve por objetivo testar a biocompatibilidade de um floculado de resina de mamona, comercialmente disponível, utilizando como modelo experimental o reparo ósseo alveolar de ratos.

*Mestre em Odontologia, Área de Reabilitação Oral (bolsista da CAPES); **Doutoranda, Área de Reabilitação Oral; ***Professores Titulares do Departamento de Morfologia, Estomatologia e Fisiologia - Faculdade de Odontologia de Ribeirão Preto da USP. 
CALIXTO, R. F. E.; TEÓFILO, J. M.; BRENTEGANI, L. G.; LAMANO CARVALHO, T. L. Implante de um floculado de resina de mamona em alvéolo dental de rato. Pesqui Odontol Bras, v. 15, n. 3, p. 257-262, jul./set. 2001.

\section{MATERIAL E MÉTODOS}

Foram utilizados 80 ratos machos Wistar (peso corporal de $180 \mathrm{~g}$ ) mantidos em condições controladas de luminosidade ( $12 \mathrm{~h}$ de luz) e temperatura $\left(22^{\circ} \pm 3^{\circ} \mathrm{C}\right)$, recebendo água e ração comercial a vontade. Os ratos controles foram submetidos à extração do incisivo superior direito e sacrificados após 1, 2, 3 e 6 semanas ( $\mathrm{n}=10$ por período); os ratos implantados receberam implante do floculado de mamona imediatamente após a extração dental, sendo sacrificados nos mesmos períodos ( $\mathrm{n}=10$ por período).

Para as extrações dentais, os animais foram anestesiados com 2,2,2 tribromoethanol (Aldrich, EUA, $25 \mathrm{mg} / 100$ g, via i.p.) e, imediatamente após a exodontia, os ratos do grupo implantado tiveram o alvéolo parcialmente preenchido com cerca de $4,0 \mathrm{mg}$ do enxerto floculado (flocos de 700-1.200 $\mu \mathrm{m}$ ) da resina de mamona (AUG-EX, Poliquil Araraquara Polimeros Químicos Ltda., Araraquara - SP), misturado em quantidade mínima de soro fisiológico e introduzido com auxílio de um porta-amálgama. Em seguida à extração ou extração + implante, os tecidos superficiais foram suturados e os ratos receberam uma dose intramuscular de 0,2 $\mathrm{ml}$ de pentabiótico veterinário (Laboratórios Wyeth-Whitehall Ltda., SP).

Os ratos foram sacrificados por decapitação e as hemimaxilas direitas fixadas, descalcificadas, processadas para inclusão em parafina e obtenção de cortes longitudinais semi-seriados corados pela hematoxilina-eosina, conforme descrito em trabalho anterior ${ }^{7}$.

\section{Análise histométrica}

A fração de volume dos elementos reparacionais da ferida de extração dental foi estimada por um método de contagem diferencial de pontos, em imagens histológicas observadas sob ocular contendo um retículo com 100 pontos eqüidistantes (aumento final de $100 \mathrm{X}$ ). Foram contados 500 pontos por alvéolo, nos períodos de 2 e 6 semanas após a extração dental, sendo a porcentagem de pontos distribuídos entre coágulo sangüíneo, tecido conjuntivo e trabéculas ósseas, proporcional ao volume relativo de cada um destes elementos. Como o material implantado preenchia parcialmente os terços médio e cervical, a cronologia do reparo foi avaliada no terço apical, apenas nos animais em que as lâminas histológicas mostraram-se adequadas para a realização de medidas ( $\mathrm{n}=5-8$ por grupo experimental).

\section{Análise estatística}

As comparações entre os grupos tratado e respectivo controle foram realizadas pelo teste $t$ de Student, após confirmação da normalidade das distribuições (GMC Basic Software, versão 7.5).

\section{RESULTADOS}

Ao final da $1^{\text {a }}$ semana pós-exodontia, a cavidade de extração encontrava-se preenchida por um tecido de granulação contendo remanescentes do coágulo sangüíneo e trabéculas ósseas imaturas (osteóide), mais abundantes nas superficies internas das corticais ósseas vestibular e palatina e no fundus alveolar. A partir da $2^{\text {a }}$ semana, observou-se neoformação óssea progressiva, paralelamente à diminuição da densidade do infiltrado inflamatório e do volume relativo de tecido conjuntivo e de remanescentes do coágulo sangüíneo, culminando, após 6 semanas, com o preenchimento da cavidade de extração por trabéculas ósseas maduras circundando espaços medulares preenchidos por tecido conjuntivo frouxo.

O material implantado, de forma irregular e tamanho variável, localizava-se entre os terços médio e cervical dos alvéolos dentais (Figura 1). Ao final da $1^{\text {a }}$ semana pós-implantação, os flocos da resina encontravam-se circundados por tecido de granulação, com a presença de trabéculas ósseas imaturas formando-se nas proximidades de sua superficie. A partir da $2^{a}$ semana, uma quantidade progressivamente maior de tecido ósseo em maturação foi observada entre e ao redor dos flocos, no geral com a presença de um tecido conjuntivo interposto, mas em algumas regiões estabelecendo um aparente contato direto com eles. Foram observadas com freqüência, em todos os periodos experimentais, áreas sem preenchimento tissular ao redor das superficies côncavas dos flocos e uma quantidade discreta de células gigantes tipo corpo estranho aderidas a sua superficie.

A análise histométrica mostrou um atraso da ordem de $13 \%$ a $20 \%$ no reparo alveolar apical dos ratos implantados, com menor neoformação óssea (significância estatística após 6 semanas) associada a maiores volumes percentuais de tecido conjuntivo (significância estatística após 6 semanas) e de coágulo sangüíneo ( 2,5 vezes maior após 2 semanas) (Tabela 1).

\section{DISCUSSÃO}

A histologia e cronologia do reparo alveolar de ratos, assim como de humanos e de outras espécies animais, estão amplamente documentadas na 
CALIXTO, R. F. E.; TEÓFILO, J. M.; BRENTEGANI, L. G.; LAMANO CARVALHO, T. L. Implante de um floculado de resina de mamona em alvéolo dental de rato. Pesqui Odontol Bras, v. 15, n. 3, p. 257-262, jul./set. 2001.
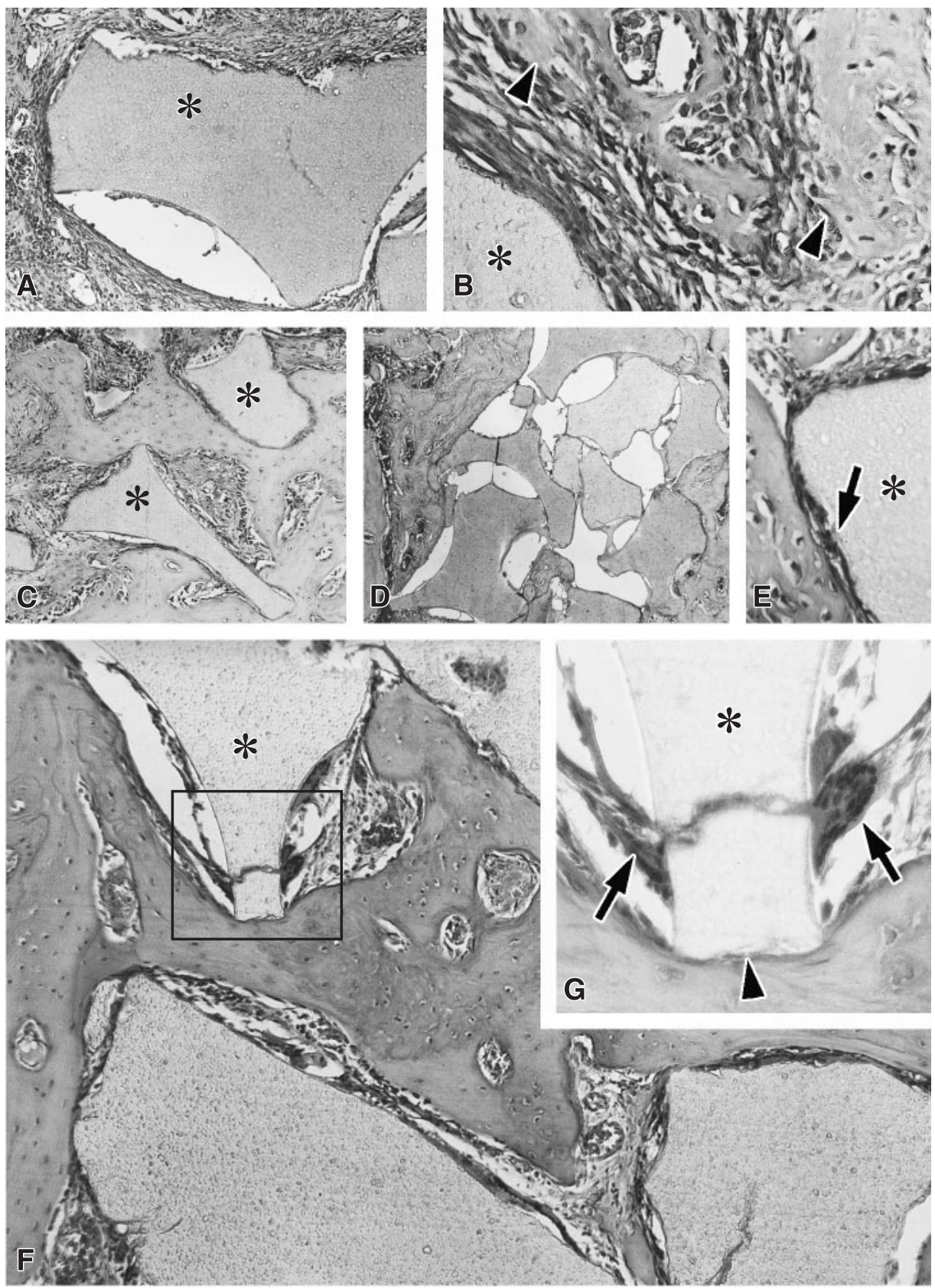

FIGURA 1 - Flocos da resina de mamona (*) circundados por tecido de granulação, com a presença de trabéculas osteóides nas proximidades de sua superficie (cabeças de setas), 1 semana após a implantação (A e B); aumento progressivo da quantidade de trabéculas ósseas ao redor e entre os flocos do material $(*)$ da $2^{\text {a }}(\mathrm{C})$ para a $6^{\mathrm{a}}$ semana (F) pós-implantação, no geral, com a presença de tecido conjuntivo interposto (E, seta) mas, em algumas áreas, estabelecendo contato aparentemente direto com sua superficie (G, cabeça de seta); D - flocos de formato irregular e tamanho variável, no terço médio do alveólo dental; células gigantes tipo corpo estranho (setas) aderidas à superfície do material implantado ( $\mathrm{F}$ e G) (H.E., $\mathrm{A}=56 \mathrm{X} ; \mathrm{B}, \mathrm{D}$ e $\mathrm{G}=100 \mathrm{X} ; \mathrm{C} \mathrm{e}$ $\mathrm{E}=25 \mathrm{X})$. literatura ${ }^{2,7,11}$. O coágulo sangüíneo que preenche a cavidade de extração imediatamente após a exodontia é progressivamente reabsorvido, à medida que é invadido por células endoteliais e fibroblastos originados de restos do ligamento periodontal, que proliferam e migram para seu interior dando origem ao tecido de granulação. A seguir, os fibroblastos originam osteoblastos que sintetizam a matriz óssea, formando um trabeculado ósseo imaturo (osteóide) que é gradativamente mineralizado pela deposição de cálcio, na forma de cristais de hidroxiapatita. A formação das trabéculas ósseas se dá de forma concêntrica, a partir do terço apical em direção ao terço cervical e das paredes vestibular e palatina para o centro do alvéolo.

No presente trabalho, as observações histológicas e os resultados histométricos do reparo alveolar dos ratos controles corroboraram os dados da literatura. Nos ratos implantados, no entanto, os resultados histométricos evidenciaram que a presença do floculado de mamona nos terços médio/cervical provocou um atraso discreto na neo- 
CALIXTO, R. F. E.; TEÓFILO, J. M.; BRENTEGANI, L. G.; LAMANO CARVALHO, T. L. Implante de um floculado de resina de mamona em alvéolo dental de rato. Pesqui Odontol Bras, v. 15, n. 3, p. 257-262, jul./set. 2001.

TABELA 1 - Fração de volume (\%) de coágulo sangüíneo e tecidos ósseo e conjuntivo no terço apical do alvéolo dental de ratos controles e implantados, nos períodos de 2 e 6 semanas após a exodontia (média \pm EPM).

\begin{tabular}{|c|c|c|c|c|}
\hline \multirow{2}{*}{$\begin{array}{c}\text { Elemento } \\
\text { reparacional }\end{array}$} & \multicolumn{2}{|c|}{2 semanas } & \multicolumn{2}{|c|}{6 semanas } \\
\hline & $\begin{array}{l}\text { Controle } \\
(n=6)\end{array}$ & $\begin{array}{c}\text { Implantado } \\
(\mathrm{n}=8)\end{array}$ & $\begin{array}{l}\text { Controle } \\
(n=5)\end{array}$ & $\begin{array}{c}\text { Implantado } \\
(\mathrm{n}=7)\end{array}$ \\
\hline $\begin{array}{c}\text { Coágulo } \\
\text { sangüíneo }\end{array}$ & $1,3 \pm 0,5$ & $3,3 \pm 0,4 * *$ & $1,1 \pm 0,5$ & $1,9 \pm 0,6$ \\
\hline $\begin{array}{c}\text { Tecido } \\
\text { conjuntivo }\end{array}$ & $42,7 \pm 1,9$ & $51,8 \pm 5,1$ & $25,9 \pm 2,3$ & $34,9 \pm 2,1 *$ \\
\hline $\begin{array}{l}\text { Trabéculas } \\
\text { ósseas }\end{array}$ & $56,0 \pm 1,7$ & $44,8 \pm 5,2$ & $73,0 \pm 2,0$ & $63,2 \pm 2,6^{*}$ \\
\hline
\end{tabular}

*,**Estatisticamente diferente do respectivo controle (teste $t$ de Student, ${ }^{*} \alpha=0,05 \mathrm{e}^{* *} \alpha=0,01$ ). $\mathrm{EPM}=$ erro padrão da média.

formação óssea no terço apical dos alveólos dentais, de alguma forma relacionado com distúrbio na organização/remissão do coágulo sangüíneo.

Sabe-se que o metabolismo ósseo é regulado por fatores locais que modulam a diferenciação, proliferação e migração celular. No caso específico do reparo ósseo alveolar, fatores de crescimento derivados do coágulo sangüíneo, tais como o fator de crescimento derivado de plaquetas (PDGF) e o fator transformador de crescimento (TGF- $\beta$ ), parecem ter particular importância. Os fibroblastos originados do ligamento periodontal expressam receptores para o PDGF e apresentam forte resposta mitogênica e quimiotáxica a este fator, in vitro, enquanto o TGF- $\beta$ inibe a proliferação de fibroblastos mas estimula a formação de osso imaturo, in vivo ${ }^{11}$. Baseados nestas evidências experimentais, LIN et $a l^{11}$ (1994) sugeriram que o PDGF derivado de plaquetas estimularia a proliferação de fibroblastos do ligamento periodontal e sua migração para o interior do coágulo sangüíneo, nos estágios iniciais do reparo, enquanto o TGF- $\beta$ seria importante na fase final de diferenciação dos fibroblastos em osteoblastos. Embora os mecanismos pelos quais a presença da resina de mamona alterou o reparo ósseo não tenham sido objeto da presente investigação, é plausivel supor uma possivel interferência com o controle local da neoformação óssea. Este é um campo de interesse para futuras investigações.

\section{Biocompatibilidade da resina de mamona}

O requisito mínimo para a implantação de materiais aloplásticos no interior de tecidos biológicos é a biocompatibilidade. Qualquer material estranho colocado no interior de tecidos vivos provoca uma resposta, e não é a resposta em si mas sua extensão, intensidade e duração que determinam a biocompatibilidade, ou seja, "um estado de mútua coexistência entre um material e o ambiente fisiológico, sem que um exerça efeito desfavorável sobre o outro" 1 .

No caso dos implantes intra-ósseos, espera-se que o material implantado seja capaz de estabelecer um contato direto com o tecido ósseo reparacional (osseointegração direta). Os biomateriais podem também estabelecer com o osso circundante uma integração indireta ou fibro-óssea, quando uma cápsula fibrosa se interpõe entre eles e a superfície do osso ${ }^{10}$, o que é aceitável apenas nos estágios iniciais pós-implantação por ser desfavorável à estabilidade dos implantes, a longo prazo.

Considera-se, hoje, que biocompatibilidade e capacidade de osseointegração não são propriedades exclusivas da composição química dos biomateriais, mas dependem também de características fisicas como tamanho, forma e quantidade de partículas, rugosidade superficial, existência e tamanho de poros ${ }^{1,4,6,10,13,15}$. Enquanto o implante de partículas grandes de material aloplástico, de forma regular e superficie lisa, costuma evocar uma resposta inflamatória de curta duração, seguida da incorporação adequada do material ao tecido hospedeiro, partículas pequenas, de forma irregular e pontiagudas, suscitam uma reação granulomatosa de células gigantes, acompanhada de destruição e reabsorção dos tecidos vizinhos ${ }^{1}$.

A biocompatibilidade da resina de mamona, com diferentes tamanhos, formas e apresentações, tem sido avaliada histologicamente em modelos experimentais diversos. O exame histológico de implantes intra-ósseos (cilindros de $0,5 \mathrm{~cm}$ ) e intra-articulares (na forma de gel) em coelhos mostrou que a resina não produz reação inflamatória tardia e, quando implantada no interior de ossos longos, produz reação fibrosa que evolui para neoformação óssea, sem sinais de rejeição ${ }^{14}$. A resina de mamona implantada na forma de fragmentos de $1 \mathrm{~mm}^{3}$ na câmara anterior do olho de camundongos mostrou-se bem tolerada, suscitando uma reação inflamatória inicial que diminuiu com o passar do tempo, apesar da presença de células gigantes que propiciou a reabsorção bastante lenta do implante ${ }^{16}$. A biocompatibilidade da resina de mamona foi comparada à do cimento de óxido de zinco e eugenol, em implantes subcutâneos dorsais realizados em ratos, e o exame histológico mostrou ní- 
CALIXTO, R. F. E.; TEÓFILO, J. M.; BRENTEGANI, L. G.; LAMANO CARVALHO, T. L. Implante de um floculado de resina de mamona em alvéolo dental de rato. Pesqui Odontol Bras, v. 15, n. 3, p. 257-262, jul./set. 2001.

vel aceitável de biocompatibilidade para ambos os materiais ${ }^{3}$.

Em trabalho anterior, testamos a biocompatibilidade da resina de mamona (C.O.R. - Composto Ósseo de Ricinus, Poliquil Araraquara Polímeros Químicos Ltda., Araraquara - SP) moldada no próprio laboratório na forma de grânulos de $1,8 \mathrm{~mm}$ de diâmetro, os quais foram implantados na cavidade de extração de incisivos superiores de ratos. O exame histológico mostrou os grânulos de formato regular localizados no terço cervical dos alvéolos dentais, circundados inicialmente por uma cápsula de natureza inflamatória, que tornou-se fibrosa e progressivamente mais delgada até que, após seis semanas, em algumas áreas, trabéculas ósseas maduras estabeleciam íntimo contato com o material implantado. Não houve persistência da reação inflamatória ou presença de células gigantes tipo corpo estranho ${ }^{8}$. Apesar de biocompativel, e à semelhança do que se observou no presente trabalho, a presença dos grânulos no terço cervical provocou um retardo discreto $(9 \%$ a $22 \%$ ) na neoformação óssea reparacional nos terços médio e apical dos alvéolos dentais ${ }^{9}$. No presente trabalho, testou-se um material floculado de formato irregular e tamanho variável (700 a $1.200 \mu \mathrm{m})$, comercialmente disponível e indicado pelo fabricante para preenchimento de falhas ósseas em Periodontia e Implantodontia, em cirurgias buco-maxilofaciais menores, para elevação de seio maxilar e para manutenção da altura do processo alveolar.
Implantado na cavidade de extração de ratos, o material mostrou-se biocompativel e capaz de certo grau de osseointegração direta, dentro do período da investigação. A presença da resina não suscitou uma resposta inflamatória persistente, em que pese a ocorrência de uma quantidade discreta de células gigantes tipo corpo estranho aderidas à sua superficie. Os flocos foram circundados por quantidades progressivamente maiores de tecido ósseo em maturação, que em algumas regiões estabelecia um aparente contato direto com os mesmos, indicando áreas de osseointegração verdadeira. No entanto, comparando com o trabalho anterior do nosso laboratório, parece que o formato irregular dos flocos não favorece a aderência aos tecidos reparacionais, uma vez que ao redor das superficies côncavas foram observadas freqüentemente áreas sem preenchimento tissular.

\section{CONCLUSÕES}

Flocos de resina poliuretana de mamona, de formato irregular e tamanho variável (700-1.200 $\mu \mathrm{m})$, implantados na cavidade de extração dental de ratos, mostraram-se biocompativeis e capazes de certo grau de osseointegração direta. No entanto, parece que o formato irregular dos flocos não favorece sua aderência aos tecidos reparacionais. A presença do material nos terços médio/cervical provocou um atraso discreto (13\% a $20 \%)$ no reparo ósseo apical.

CALIXTO, R. F. E.; TEÓFILO, J. M.; BRENTEGANI, L. G.; LAMANO CARVALHO, T. L. Implantation of flakes of castor oil resin in rat dental alveolus. Pesqui Odontol Bras, v. 15, n. 3, p. 257-262, jul./set. 2001.

The purposes of the present study were: 1 ) to investigate the biocompatibility of a natural resin (made of fatty acids extracted from Ricinus communis) implanted in the dental alveolus of rats and 2) to verify any possible interference of that material in the osseous healing following tooth extraction. The resin (AUG-EX, Poliquil Araraquara Polimeros Químicos LTDA, Araraquara - SP) was placed inside de alveoli immediately after extraction of the upper right incisors. The animals were sacrificed 1, 2, 3 and 6 weeks after extraction or extraction + implantation. The hemi-maxillae were decalcified and processed for paraffin embedding. Longitudinal 6-micrometer-thick semi-serial sections stained with hematoxylin and eosin were obtained. Histologic examination showed particles of irregular shape and variable size (700-1200 $\mu \mathrm{m})$ localized in the medium/cervical alveolar thirds, with a scanty but persistent foreign body reaction. From the second week on, as the relative volume of bone trabeculae increased, it was seen in close contact with the surface of the implanted material in some regions. Histometric analysis (differential point counting method), used to quantify the healing process in the apical third, showed a small but significant decrease (13\%-20\%) in new bone formation in the implanted rats. In conclusion, the results show that, in spite of its biocompatible nature, the studied resin hinders the post-extration healing process.

UNITERMS: Biocompatibility; Ricinus communis; Resins. 
CALIXTO, R. F. E.; TEÓFILO, J. M.; BRENTEGANI, L. G.; LAMANO CARVALHO, T. L. Implante de um floculado de resina de mamona em alvéolo dental de rato. Pesqui Odontol Bras, v. 15, n. 3, p. 257-262, jul./set. 2001.

\section{REFERÊNCIAS BIBLIOGRÁFICAS}

1. BOSS, J. H.; SHAJRAWI, I.; AUNULLAH, J.; MENDES, D. G. The relativity of biocompatibility. A critical of the concept of biocompatiblity. Israel J Med Sci, v. 31, n. 4, p. 203-209, 1995.

2. CARVALHO, A. C. P.; OKAMOTO, T. Reparação do alvéolo dental. In: CARVALHO, A. C. P.; OKAMOTO, T. Cirurgia bucal. Fundamentos experimentais aplicados à clínica. São Paulo : Editorial Médica Panamericana, 1987. p. $55-80$.

3. COSTA, C. A. S.; MARCANTONIO, R. A. C.; HEBLING, J. et al. Biocompatibilidade do polímero de poliuretana vegetal derivada do óleo de mamona em estudo comparativo com cimento de óxido de zinco e eugenol. Avaliação histopatológica de implantes subcutâneos de ratos. Odonto 2000, v. 1, n. 1, p. 44-48, 1997.

4. FURUSAWA, T.; MIZUNUMA, K.; YAMASHITA, S.; TAKAHASHI, $T$. Investigation of early bone formation using resorbable bioactive glass in the rat mandibule. Int J Oral Maxillofac Implants, v. 13, p. 672-676, 1998.

5. IGNÁCIO, H. Utilização do cimento derivado do polimero da mamona no preenchimento da falha óssea. Estudo experimental em coelhos. Ribeirão Preto, 1995. 96 p. Dissertação (Mestrado) - Faculdade de Medicina de Ribeirão Preto, Universidade de São Paulo.

6. KIESWETTER, K.; SCHWARTZ, Z.; DEAN, D. D.; BOYAN, B. D. The role of implant surface characteristics in the healing of bone. Crit Ver Oral Biol Med, v. 7, n. 4, p. 329-345, 1996.

7. LAMANO CARVALHO, T. L.; BRENTEGANI, L. G.; BOMBONATO, K. F. Histometric analysis of rat alveolar wound healing. Braz Dent J, v. 8, n. 1, p. 9-12, 1997.

8. LAMANO CARVALHO, T. L.; ALBUQUERQUE ARAÚJO, C. A. C.; TEÓFILO, J. M.; BRENTEGANI, L. G. Histologic and histometric evaluation of rat alveolar wound healing around polyurethane resin implants. Int J Oral Maxillofac Surg, v. 26, p. 149-152, 1997a.

9. LAMANO CARVALHO, T. L.; TEÓFILO, J. M.; ALBUQUERQUE ARAÚJO, C. A. C.; BRENTEGANI, L. G. Chronology of alveolar healing following immediate implantation of Ricinus communis polyurethane resin: histometric analysis in rats. J Biomed Mater Res, v. 37, p. 449-452, 1997b.

10. LeGEROS, R. Z.; CRAIG, R. G. Strategies to affect bone remodeling: osteointegration. J Bone Mineral Res, v. 8, p. S583-S596, 1993. Supplement 2.

11. LIN, W. L.; McCULLOCH, C. A. G.; CHO, M. I. Differentiation of periodontal ligament fibroblasts into osteoblasts during socket healing after tooth extraction in the rat. Anat Rec, v. 240, p. 492-506, 1994.

12. MAGRO-FILHO, O; GARCIA Jr., I. R.; OKAMOTO, T. et al. Implante de polímero de mamona em cavidades cirúrgicas experimentais realizadas em tíbia. Estudo histológico em ratos. Innovations Magazine, v. 2, n. 2, p. 10-14, 1998.

13. MISIEK, D. J.; KENT, J. N.; CARR, R. F. Soft tissue responses to hydroxylapatite particles of different shapes. $\mathbf{J}$ Oral Maxillofac Surg, v. 42, p. 150-160, 1984.

14. OHARA, G. H.; KOJIIMA, K. E.; ROSSI, J. C. et al. Estudo experimental da biocompatibilidade do polimero poliuretano da mamona implantada intra-óssea e intra-articular em coelhos. Acta Ortop Bras, v. 3, n. 2, p. 62-68, 1995.

15. SHAPOFF, C. A.; BOWERS, G. M.; LEVY, B. et al. The effect of particle size on the osteogenic activity of composite grafts of allogeneic freeze-dried bone and autogenous marrow. J Periodontol, v. 51, n. 11, p. 625-630, 1980.

16. VILARINHO, R. H.; HETEM, S., Implante de resina poliuretana vegetal na câmara anterior do olho de camundongo. Odonto 2000, v. 1, p. 25-29, 1996.

Recebido para publicação em $24 / 10 / 00$

Enviado para reformulação em 26/03/01 Aceito para publicação em 02/05/01 